\title{
Temperature instability during nursing procedures in preterm neonates
}

\author{
Q Mok, C A Bass, D A Ducker, N McIntosh
}

\begin{abstract}
The temperature changes associated with total care nursing procedures were studied on 249 occasions during the first week of life in 25 preterm infants weighing less than $1500 \mathrm{~g}, 16$ of whom weighed less than $1100 \mathrm{~g}$. Large drops in both central and peripheral temperature occurred, with widening of the centralperipheral temperature gap. Recovery of the temperature after the total care procedure took up to two hours.

These routine nursing procedures are carried out every four to six hours. They cause an important alteration in the environmental temperature with consequent thermal stress to the infants that may influence ultimate outcome.
\end{abstract}

There is a narrow range of ambient temperature within which the metabolic rate and oxygen demand of neonates are minimal. ${ }^{1}$ This neutral thermal environment varies with an infant's body weight, age, and amount of clothing, ${ }^{2} 3$ and is important because babies managed at environmental temperatures outside this range may grow less adequately, ${ }^{4}$ and be at risk of increased mortality and morbidity. ${ }^{5-7}$

Without outside help the preterm baby behaves like a classic poikilotherm, its temperature reflecting that of its surroundings. ${ }^{89}$ The provision of a neutral thermal environment with incubators and overhead heaters is an important feature of neonatal intensive care. In 1985 we reported temperature fluctuations that occurred during the handling of babies, ${ }^{10}$ and showed that they were more pronounced when the incubator was used in a servo controlled temperature mode. ${ }^{11}$ The aim of the present study was to monitor the degree and importance of these temperature changes during handling.

\section{Patients and methods}

Temperature recordings were collected from 25 very low birthweight babies (less than $1500 \mathrm{~g}$ ) admitted to the neonatal intensive care unit at this hospital. The infants were subdivided into those weighing above and below $1100 \mathrm{~g}$, as infants weighing less than $1100 \mathrm{~g}(\mathrm{n}=16)$ were nursed in humidified incubators for the first 14 days. The babies were routinely nursed naked and covered by a single layer of bubble plastic in closed incubators the air in which was controlled at the temperature of the infant's neutral thermal environment. ${ }^{11}$ The temperature of the nursery was set at $28^{\circ} \mathrm{C}$ and the humidity at $40 \%$.
Total care nursing procedures that were carried out during the first week of life were monitored. These consisted of mouth care, measurement of axillary temperature, nappy change, turning, heel pricking for measurement of blood glucose concentration, and rotation of transcutaneous probe sites. If the infant was ventilated, physiotherapy and endotracheal tube suction would often be included. This routine, performed four to six hourly, took about 20 minutes to complete but could vary from 15 to 45 minutes, depending on the nurse and the tasks required. Temperature probes were attached to the abdominal skin and the sole of the foot to measure core and peripheral temperatures, respectively. These measurements were recorded continuously by Simonsen and Weel 8000 series monitors and were fed into the MARY neonatal monitoring system installed in the unit. ${ }^{12}$ This system (Meadowbank Medical Systems Limited) can record up to 16 channels of physiological and environmental data from each intensive care cot. Data were obtained every second, averaged every minute, and stored on the hard disk of the host computer.

\section{Results}

The birth weights of the babies ranged from 510 to $1500 \mathrm{~g}$ (median 920). The babies were born at gestational ages ranging from 24 to 31 weeks (median 27). The temperature changes from a total of 249 total care procedures carried out during the first week of life were analysed. Figure 1 shows typical graphs of core and peripheral temperature fluctuations during total care procedures obtained from four of the babies during the study. There is generally a temperature gap reflecting the higher central temperature compared with the extremities. At the end of each total care procedure there was an obvious fall in both central and peripheral temperature in all babies. The peripheral temperature fell by a greater degree after total care such that the central-peripheral temperature gap widened. Recovery to the temperature before the procedure was gradual and could take as long as two hours.

The data obtained from the 249 procedures on the 25 babies are shown in the table. The central temperature fell by a mean of $0.7^{\circ} \mathrm{C}$ (range $0 \cdot 0-1 \cdot 7$ ) and the peripheral temperature by $1.3^{\circ} \mathrm{C}$ (range $0 \cdot 2-3.0$ ). The temperature gap widened by an average of $0.6^{\circ} \mathrm{C}$ (range $0 \cdot 0-2 \cdot 7$ ) after total care procedures. The lowest central temperature recorded was $34.8^{\circ} \mathrm{C}$ in a baby of 26 weeks' gestation who weighed $800 \mathrm{~g}$, and the 
lowest peripheral temperature recorded was $32 \cdot 6^{\circ} \mathrm{C}$ in a baby of 24 weeks' gestation who weighed $770 \mathrm{~g}$. In one infant the temperature gap increased from $0.3^{\circ} \mathrm{C}$ at the start of a procedure to $3 \cdot 0^{\circ} \mathrm{C}$ at the end.

Figure 2 shows the association between central and peripheral temperature changes and
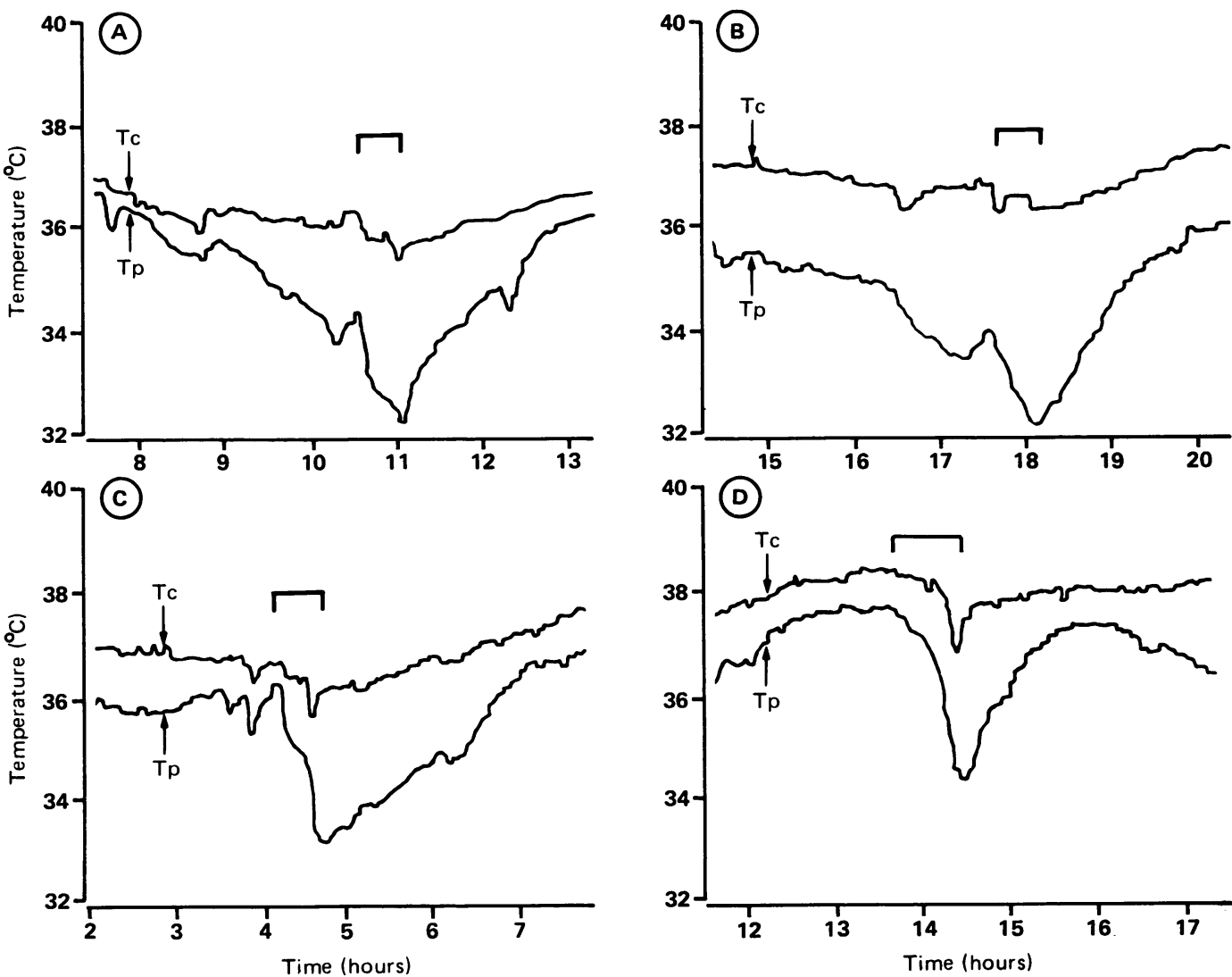

Figure 1 Examples of graphs obtained from different babies during total care procedures showing temperature fluctuations with time. In each graph the upper $(T c)$ and lower $(T p)$ trace indicates the central and peripheral temperatures respectively. Periods of total care are indicated by $\square$. The babies' gestational ages, birthweights, and times of recording, respectively, were: (A) 31 weeks, $1500 \mathrm{~g}$, day 5; (B) 28 weeks, $920 \mathrm{~g}$, day 2; (C) 24 weeks, $770 \mathrm{~g}$, day 3; and (D) 27 weeks, $1000 \mathrm{~g}$, day 7 .

Details of 25 babies. Each temperature value is the mean of a series of total care procedures for each baby

\begin{tabular}{|c|c|c|c|c|c|c|c|c|c|c|}
\hline \multirow{2}{*}{$\begin{array}{l}\text { Case } \\
\text { No }\end{array}$} & \multirow{2}{*}{$\begin{array}{l}\text { Gestation } \\
\text { (weeks) }\end{array}$} & \multirow{2}{*}{$\begin{array}{l}\text { Weight } \\
(\mathrm{g})\end{array}$} & \multirow{2}{*}{$\begin{array}{l}\text { No of } \\
\text { procedures }\end{array}$} & \multicolumn{3}{|c|}{ Central temperature $\left({ }^{\circ} \mathrm{C}\right)$} & \multicolumn{3}{|c|}{ Peripheral temperature $\left({ }^{\circ} \mathrm{C}\right)$} & \multirow{2}{*}{$\begin{array}{l}\text { Central- } \\
\text { peripheral } \\
\text { difference } \\
\left({ }^{\circ} \mathrm{C}\right)\end{array}$} \\
\hline & & & & $\begin{array}{l}\text { Before total } \\
\text { care } \\
\text { procedure }\end{array}$ & $\begin{array}{l}\text { After total } \\
\text { care } \\
\text { procedure }\end{array}$ & Difference & $\begin{array}{l}\text { Before total } \\
\text { care } \\
\text { procedure }\end{array}$ & $\begin{array}{l}\text { After total } \\
\text { care } \\
\text { procedure }\end{array}$ & Difference & \\
\hline 1 & 27 & 510 & 17 & $37 \cdot 7$ & $36 \cdot 8$ & 0.9 & 36.9 & 34.9 & $2 \cdot 0$ & $1 \cdot 1$ \\
\hline 2 & 24 & 630 & 7 & $37 \cdot 5$ & $37 \cdot 1$ & 0.4 & $36 \cdot 3$ & $34 \cdot 6$ & $1 \cdot 7$ & $1 \cdot 3$ \\
\hline 3 & 26 & 640 & 11 & $37 \cdot 6$ & $36 \cdot 4$ & $1 \cdot 2$ & $36 \cdot 7$ & $34 \cdot 8$ & 1.9 & 0.7 \\
\hline 4 & 24 & 770 & 8 & $37 \cdot 8$ & $37 \cdot 1$ & 0.7 & $36 \cdot 6$ & $34 \cdot 7$ & 1.9 & $1 \cdot 2$ \\
\hline 5 & 27 & 790 & 17 & $37 \cdot 7$ & $36 \cdot 7$ & 1.0 & 36.9 & $35 \cdot 4$ & 1.5 & 0.5 \\
\hline 6 & 26 & 800 & 6 & $37 \cdot 2$ & $36 \cdot 3$ & 0.9 & $36 \cdot 3$ & $35 \cdot 1$ & $1 \cdot 2$ & $0 \cdot 3$ \\
\hline 7 & 28 & 820 & 15 & $36 \cdot 9$ & $36 \cdot 2$ & 0.7 & $36 \cdot 4$ & $35 \cdot 0$ & 1.4 & 0.7 \\
\hline 8 & 28 & 820 & 5 & $37 \cdot 5$ & $37 \cdot 1$ & 0.4 & $36 \cdot 3$ & 34.9 & 1.4 & 1.0 \\
\hline 9 & 26 & 850 & 11 & $37 \cdot 3$ & $36 \cdot 8$ & 0.5 & $36 \cdot 4$ & 34.9 & 1.5 & 1.0 \\
\hline 10 & 28 & 870 & 3 & $37 \cdot 9$ & $37 \cdot 1$ & 0.8 & $36 \cdot 3$ & $35 \cdot 5$ & 0.8 & 0.0 \\
\hline 11 & 27 & 890 & 6 & 36.9 & $36 \cdot 1$ & 0.8 & $36 \cdot 1$ & $35 \cdot 0$ & $1 \cdot 1$ & $0 \cdot 3$ \\
\hline 12 & 28 & 900 & 16 & $37 \cdot 0$ & $36 \cdot 3$ & 0.7 & $36 \cdot 1$ & $34 \cdot 8$ & $1 \cdot 3$ & 0.6 \\
\hline 13 & 28 & 920 & 9 & $37 \cdot 3$ & $36 \cdot 7$ & 0.6 & $36 \cdot 5$ & $35 \cdot 5$ & 1.0 & 0.4 \\
\hline 14 & 27 & 1000 & 20 & $37 \cdot 9$ & $37 \cdot 4$ & 0.5 & $36 \cdot 4$ & $35 \cdot 4$ & 1.0 & 0.5 \\
\hline 15 & 26 & 1020 & 9 & $38 \cdot 1$ & $37 \cdot 5$ & 0.6 & $36 \cdot 5$ & $35 \cdot 5$ & 1.0 & 0.4 \\
\hline 16 & 27 & 1060 & 8 & $37 \cdot 5$ & $37 \cdot 0$ & 0.5 & $36 \cdot 5$ & $35 \cdot 7$ & 0.8 & $0 \cdot 3$ \\
\hline 17 & 28 & 1170 & 9 & $36 \cdot 8$ & $36 \cdot 1$ & 0.7 & $35 \cdot 9$ & $34 \cdot 8$ & $1 \cdot 1$ & 0.4 \\
\hline 18 & 28 & 1200 & 6 & $37 \cdot 1$ & $36 \cdot 3$ & 0.8 & $36 \cdot 6$ & $35 \cdot 3$ & $1 \cdot 3$ & 0.5 \\
\hline 19 & 29 & 1270 & 14 & $36 \cdot 9$ & $36 \cdot 4$ & 0.5 & $36 \cdot 1$ & $35 \cdot 2$ & 0.9 & 0.4 \\
\hline 20 & 28 & 1280 & 4 & $36 \cdot 9$ & $36 \cdot 2$ & 0.7 & $36 \cdot 6$ & $35 \cdot 3$ & $1 \cdot 3$ & 0.6 \\
\hline 21 & 30 & 1310 & 5 & $38 \cdot 0$ & $37 \cdot 4$ & 0.6 & $36 \cdot 7$ & $35 \cdot 4$ & $1 \cdot 3$ & 0.7 \\
\hline 22 & 31 & 1350 & 4 & $37 \cdot 6$ & $37 \cdot 1$ & 0.5 & $36 \cdot 8$ & $35 \cdot 5$ & $1 \cdot 3$ & 0.8 \\
\hline 23 & 27 & 1385 & 14 & $37 \cdot 0$ & $36 \cdot 4$ & 0.6 & $35 \cdot 5$ & $34 \cdot 5$ & 1.0 & 0.4 \\
\hline 24 & 29 & 1410 & 13 & $37 \cdot 3$ & $36 \cdot 8$ & 0.5 & $36 \cdot 1$ & 34.9 & $1 \cdot 2$ & $0 \cdot 7$ \\
\hline 25 & 31 & 1500 & 12 & $37 \cdot 3$ & $36 \cdot 4$ & 0.9 & $36 \cdot 2$ & $34 \cdot 5$ & $1 \cdot 7$ & 0.8 \\
\hline
\end{tabular}




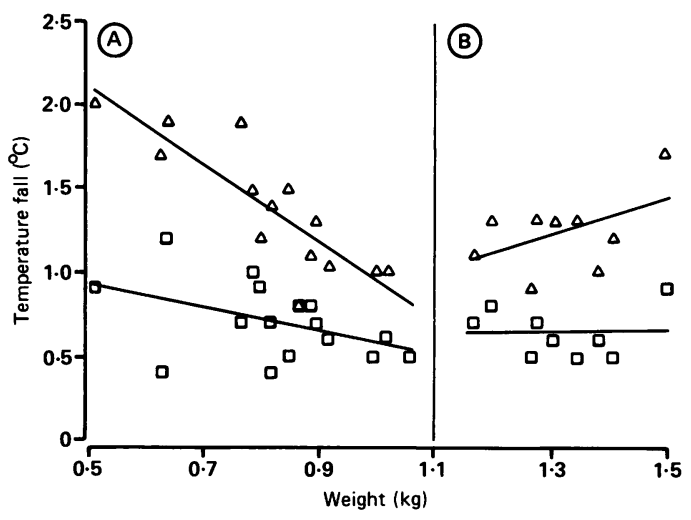

Figure 2 The association between central (squares) and peripheral (triangles) temperature changes with weight for babies $(A)<1100 \mathrm{~g}$ and $(B) \geqslant 1100 \mathrm{~g}$. A linear regression best fit line was calculated for each group; only the peripheral temperature drop in babies $<1100 \mathrm{~g}$ was significant $(p<0.0001)$.

$\mathrm{p}=0.087$ ). In babies who weighed $1100 \mathrm{~g}$ or more, and who were nursed in non-humidified incubators (fig 2B), neither the central ( $r=0.036$, $p=0.889)$ nor the peripheral $(r=0.488$, $\mathrm{p}=0 \cdot 181)$ temperature changes were significantly correlated with weight. There was no significant correlation between the temperature changes and gestational age.

\section{Discussion}

Heat is dissipated to the environment by radiation, convection, evaporation, and conduction, although heat loss from conduction is negligible from an infant managed in the neonatal intensive care unit. This study has shown that there is a significant temperature instability during routine total care nursing procedures. The change in temperature is often substantial-as much as $2 \cdot 4^{\circ} \mathrm{C}$ centrally and $3 \cdot 0^{\circ} \mathrm{C}$ peripherallywith slow recovery to normal.

Previous work showed that heat losses are more pronounced for preterm compared with term infants because of the relatively large body surface areas, poor fat insulation, thin epidermal layers, and increased peripheral blood flow in premature babies. The immature homoeostatic reflexes for maintaining body temperature in these infants also contribute to the fall in temperature and the slow recovery, as it has been shown that preterm babies are unable to increase heat producion to any appreciable extent. ${ }^{89}$ These factors account for the higher heat loss, most notable in the periphery, in the lighter babies in our study. Heat loss would probably be more severe if these babies had not been incubated under humidified conditions in which heat loss by evaporation was minimal. The greater temperature drop in some of the heavier babies may be the result of higher heat loss by evaporation in non-humidified incubators.

Despite our attempts to maintain babies within the ideal thermal environment, there was an unavoidable fall in incubator temperature and humidity when portholes were opened for nursing care. Although we did not continuously monitor details of the incubator air temperature and humidity, it has previously been shown that incubator temperatures inevitably fall when the portholes or doors are opened. ${ }^{13}$ In the small, sick infants in this study this led to a drop in the infants' temperature which only regained the normal values after about two hours.

In full term infants, hypothermia leads to an increase in the metabolic rate (and therefore oxygen demand) as the infant attempts to generate heat to regain normal temperatures. ${ }^{14}{ }^{15}$ In preterm infants with respiratory problems this may result in increased oxygen demand in a neonate whose oxygen requirements are already raised. This increased metabolic rate can cause acidosis, hypoglycaemia, and poor weight gain, ${ }^{4}$ and if the baby already has respiratory difficulties, it may contribute to respiratory failure. Sauer et al reported that in preterm infants changes in body temperature are not always accompanied by increased oxygen consumption $^{3}$; they redefined the neutral thermal environment as 'the ambient temperature at which the core temperature of the infant at rest is between 36.7 and $37.3^{\circ} \mathrm{C}$ and the core and mean skin temperatures are changing less than 0.2 and $0.3^{\circ} \mathrm{C} /$ hour, respectively'. During the total care nursing procedures, this neutral thermal environment was obviously disturbed and did not recover for some time. We have no information from our study about whether the temperature was regained by an increase in metabolic rate or by a decrease in the rate of heat loss to the surroundings (by a reduction in the gradient from the baby to incubator) thus allowing the heat generated by the babies' stable metabolic rate to accumulate.

It is our routine practice to monitor the peripheral and central temperatures of all preterm and low birthweight babies admitted to our unit. This is done by a graphical display at the cotside (fig 1). Close attention can be given to monitoring temperature changes during total care and other nursing and medical procedures. The procedures have now been modified to minimise fluctuations in temperature. For small babies the nurses increase the incubator temperature by one degree before their total care routine, and try to do the various tasks as quickly as possible, keeping a close watch on the monitor screen during the process. The visual feedback given by the computer as the procedure is carried out is important in reducing the thermal instability and possibly the thermal stress and metabolic demands on the baby.

We thank the nurses for their cooperation in this study, in particular for the care of patients and entry of the data.

1 Hey EN. Thermal neutrality. Br Med Bull 1975;31:69-74. 2 Hey EN, Katz G. The optimum thermal environment for naked babies. Arch Dis Child 1970;45:328-34.

3 Sauer PJJ, Dane HJ, Visser HKA. New standards for neutral thermal environment of healthy very low birthweight

infants in week one of life. Arch Dis Child 1984;59:18-22. 年, L, Silverman WA, Sinclair JC. Effect of thermal environment on cold resistance and growth of small infants after the first week of life. Pediatrics 1968;41:1033-46. Buetow KC, Klein $\mathrm{SW}$. Effect of maintenance of 'normal'
skin temperature on survival of infants of low birth weight. Pein temperature on survival

6 Silverman WA, Fertig JW, Berger AP. The influence of the 
thermal environment upon the survival of newly born premature infants. Pediatrics 1958;22:876-86.

7 Day RL, Caliguiri L, Kamenski C, Ehrlich F. Body temperature and survival of premature infants. Pediatrics 1964;34: 171-81.

8 Bruck K. Temperature regulation in the newborn infant. Bio Neonate 1961;3:65.

Wheldon AE, Hull D. Incubation of very immature infants. Arch Dis Child 1983;58:504-8.

10 Ducker DA, Lyon AJ, Ross Russell R, Bass CA, McIntosh $\mathrm{N}$. Incubator temperature control: effects on the very low birthweight infant. Arch Dis Child 1985;60:902-7.

11 Ducker DA, Lyon AJ, Wheeler KA, McIntosh N, Bass CA Temperature variability of very low birthweight infants nursed in infant servo controlled incubators. In: Rolfe P ed. Neonatal physiological measurements. Proceedings of the Second International Conference on Fetal and Neonatal Physiological Measurements. London: Butterworth, 1984:13-20.

12 McIntosh N, Ducker DA Bass CA MARY - a computerised neonatal cot monitoring system. Intensive Therapy and Clinical Monitoring 1989;10:272-82.

13 Alg $\mathrm{EW}$. Environmo

in intensive care. Int Anesthesiol Clin 1974;12:173-215.

14 Scopes JW, Ahmed J. Minimal rates of oxygen consumption in sick and premature newborn infants. Arch Dis Child 1966;41:407-16

15 Bell EF, Gray JC, Weinstein WR, Oh W. The effects of thermal environment on heat balance and insensible water loss in low birthweight infants. $\mathcal{F}$ Pediatr 1980;96:452-9. 